\title{
Endocrine manifestations of ovarian lesions in children: an 11 year review
}

\author{
K S H de Silva ${ }^{1}$, G L Warne ${ }^{2}$ \\ Sri Lanka Journal of Child Health, 2001; 30: 60-5
}

(Key words: Endocrine manifestations, ovarian lesions, ultrasonography)

\begin{abstract}
Objective To describe the clinical and ultrasonographic features of children with ovarian lesions presenting with endocrine manifestations.

Method The records of patients under 12 years of age with ovarian lesions admitted to the Royal Children's Hospital in Melbourne, Australia during an 11 year period were retrospectively reviewed. Patients presenting with endocrine manifestations were identified and further analysed.
\end{abstract}

Results Out of 49 patients $<12$ years of age presenting with ovarian lesions, 7 had endocrine manifestations. Their ages ranged from 6 months to 11.6 years. 3 patients each had early onset of puberty and precocious puberty while one had evidence of virilisation. These were found in association with both benign and malignant ovarian lesions. A palpable abdominal mass was found in 3 patients. The size of the lesion on ultrasound scan was recorded in 4 patients and the consistency in 6 . Two patients had lesions $>10 \mathrm{~cm}$ and in 3 the consistency was recorded as being complex (cystic and solid).

Conclusion Endocrine manifestations associated with ovarian lesions are rare in children. But a girl presenting with abnormal pubertal changes should be evaluated carefully as these features can be associated with benign and malignant tumours of the ovary as well as with physiological cysts.

\section{Introduction}

The Royal Children's Hospital is the larger of two tertiary hospitals for children and adolescents in Victoria offering care for a population of 4.7 million ${ }^{1}$. Approximately 10,000 patients per year are admitted for surgery and conditions affecting the ovary are an important cause for such admissions. Disorders affecting sexual development related to lesions of the ovary are rare. The objective of this study was to

\footnotetext{
${ }^{1}$ Senior Lecturer in Paediatrics, Faculty of Medicine, Colombo. ${ }^{2}$ Senior Endocrinologist, Dept. of Endocrinology and Diabetes, Royal Children's Hospital, Parkville, Victoria 3052, Australia.
}

describe the patients with ovarian lesions presenting with disorders of puberty to this hospital and their clinical and ultrasonographic features.

\section{Method}

The records of all children under 12 years admitted to the Royal Children's Hospital over an 11 year period from 1989 to 1999 inclusive, where ultrasonography and/or surgery revealed the possibility of an ovarian cause for their symptoms, were reviewed. The patients for the study were identified through the computer database of the hospital medical records. The records of the patients with endocrine manifestations were examined in detail. The ovarian lesions were classified as either neoplastic or non neoplastic, with physiological cysts and torsion of the ovary being considered under non neoplastic lesions. The ultrasound appearance of the ovarian lesions were defined as cystic, solid or complex (both cystic and solid) $)^{2,3}$. The size of the lesion was taken to be identical to the maximum diameter recorded (out of two or three dimensions) and categorized as $<10 \mathrm{~cm}$ and $>10 \mathrm{~cm}^{2,3}$.

\section{Results}

A total of 49 records were analyzed. The ages of the patients ranged from 2 days to 12 years. Eight patients $(16.3 \%)$ were under 1 year of age. Physiological cysts were found in 15 patients $(30.6 \%)$ and 26 patients had neoplasms. Two patients had surgery for bilateral streak gonads which did not show any evidence of neoplastic changes. Ovarian torsion was seen in 6 patients which was associated with physiological cysts in two (Table $1)$.

Table 1

Types of ovarian pathology

\begin{tabular}{|l|c|}
\hline \multicolumn{1}{|c|}{ Type } & Number \\
\hline Physiological cysts & 15 \\
\hline Neoplastic lesions & 26 \\
\hline Ovarian torsion* & 06 \\
\hline $\begin{array}{l}\text { Streak gonads without } \\
\text { tumour }\end{array}$ & 02 \\
\hline Total & 49 \\
\hline
\end{tabular}

* No associated cyst or tumour in 04 
Twenty six patients (53.1\%) had ovarian neoplasms. Differentiated cystic teratoma or dermoid cyst was the commonest tumour and was found in 21 patients. Two patients had benign tumours other than dermoid cysts and 1 had a malignant tumour. Two patients had borderline lesions of stromal origin. The two patients with bilateral streak gonads had Campomelic dysplasia $^{4}$ and Denys-Drash syndrome ${ }^{5}$ associated with XY complete gonadal dysgenesis. There were no deaths attributed to the ovarian tumours in this series. Table 2 is a summary of the ovarian neoplasms found in this series.

Table 2

$\begin{gathered}\text { Classification and distribution of } \\ \text { ovarian tumours* }\end{gathered}$
Class
Germ cell tumours
Benign
Mature cystic teratoma
$\quad$ (Dermoid cyst)
Malignant
Mixed teratoma and embryonal
carcinoma
Epithelial tumours
Benign
Mucinous cystadenoma
Sex cord-stromal tumours
Benign
Stromal tumour with focal
proliferation of thecal cells
Borderline
Juvenile granulosa cell tumour
Sertoli-Leydig cell tumour
Total

Seven patients (14.3\%) had endocrine manifestations in the form of early or precocious puberty or virilisation. The clinical manifestations and the associated ovarian lesions are summarized in Table 3. The ages of these patients ranged from 6 months to 11 years 7 months. Both non neoplastic and neoplastic lesions were associated with these features shown in Table 3 that disappeared in the majority of the children with removal of the ovarian lesion. A mass was felt abdominally in 3 patients. The gonadotrophin levels were suppressed in 6 patients and 3 had elevated serum oestradiol levels - Table 4a. On ultrasonography of the abdomen, 2 patients had ovarian lesions $>10 \mathrm{~cm}$ in size and the consistency was recorded as complex in 3 . These findings are summarized in Table $4 \mathrm{~b}$. The following is a brief description of these 7 patients.

\section{Case 1}

KS presented at the age of 6 years and 4 months with a 3-month history of breast development, appearance of pubic hair and menstrual bleeding. Examination of the abdomen was normal but pelvic ultrasonography showed a multilocular cystic lesion of the left ovary. The 24 hour urinary oestradiol was $<1 \mathrm{pmol} / 1$ and the gonadotrophin levels were undetectable $(\mathrm{FSH}<1 \mathrm{u} / \mathrm{l}$, LH $<2 \mathrm{u} / 1)$. The $10 \times 7 \times 7 \mathrm{~cm}$ ovarian cyst which was removed at laparotomy was histologically a follicular cyst with no evidence of malignancy. The pubertal changes regressed gradually during follow up.

\section{Case 2}

$\mathrm{AF}$, a 10 year and 3 month old girl presented with early onset of puberty of 6 months duration and abdominal pain associated with distension and vomiting of 3 weeks duration. Examination revealed a non tender, mobile abdominal mass. The levels of serum CA125, inhibin, LDH and oestradiol were raised with normal levels of alpha FP, BHCG and carcinoembryonic antigen while the FSH and $\mathrm{LH}$ levels were undetectable $[<0.3 \mathrm{u} / 1(<3 \mathrm{u} / 1)$ and $<0.1 \mathrm{u} / 1$ $(<3 \mathrm{u} / \mathrm{l})$ respectively]. She had a normal female karyotype. Ultrasonography showed a multiloculated cystic lesion arising from the pelvis which on laparotomy was a $27 \times 17 \times 11 \mathrm{~cm}$ cystic mass arising from the left ovary. Histology revealed chronic torsion of the ovarian pedicle with massive ovarian oedema with no evidence of malignancy in either the ovary or the omental biopsy. Two months later her breast development had regressed and the CA125 and LDH levels had normalised with a reduction of the oestradiol levels while the FSH and LH showed a pubertal response. 
Table 3

Ovarian lesions with endocrine manifestations

\begin{tabular}{|c|c|c|c|}
\hline Lesion & $\begin{array}{l}\text { Age at } \\
\text { presentattion (yrs) }\end{array}$ & Number & Clinical manifestation \\
\hline Follicular cyst & 6.3 & 01 & Precocious puberty \\
\hline $\begin{array}{l}\text { Ovarian torsion with } \\
\text { massive ovarian oedema }\end{array}$ & 10.3 & 01 & Early puberty \\
\hline Mucinous cystadenoma & 11.6 & 01 & Early puberty \\
\hline $\begin{array}{l}\text { Stromal tumour with focal- } \\
\text { proliferation of thecal cells }\end{array}$ & 9.3 & 01 & Early puberty \\
\hline Juvenile granulosa cell tumour & 0.5 & 01 & Precocious puberty \\
\hline Sertoli-Leydig cell tumour & 1.3 & 01 & Virilisation \\
\hline $\begin{array}{l}\text { Mixed teratoma and } \\
\text { embryonal carcinoma }\end{array}$ & 7.2 & 01 & Precocious puberty \\
\hline Total & & 07 & \\
\hline
\end{tabular}

Table 4a

Abdominal findings and hormonal assays in patients with endocrine manifestations

Palpable abdominal
mass

03

$$
\begin{aligned}
& \text { Increased }^{*} \\
& \text { oestradiol }
\end{aligned}
$$

03
Increased gonadotrophin:

Number of patients 01

* Not done in one patient

Table 4b

Ultrasonographic features of the patients with endocrine manifestations

Ultrasonographic appearance of lesions ${ }^{*}$
cystic
solid
complex

Number of patients

02

01

03

\section{Site of lesions $(\mathrm{cm})^{\star \star}$ \\ $<10 \mathrm{~cm} \quad>10 \mathrm{~cm}$}

Number of patients

02

02

- Not recorded in 1 patient

** Not recorded in 3 patients 


\section{Case 3}

ZW presented at 11 years and 7 months with a 6 month history of progressive abdominal distension. She had early pubertal development from around 9 years with menarche at 10 years and 8 months. An ill defined abdominal mass found on palpation was confirmed on ultrasonography to be a complex cyst of ovarian origin, $25 \mathrm{~cm}$ in diameter. Her FSH, LH and oestradiol levels were consistent with the pubertal stage and her alpha FP, BHCG and $\mathrm{LDH}$ levels were normal. A multiloculated left sided ovarian cyst was found on laparotomy and a salpingo-oophorectomy was performed. Histology revealed a benign mucinous cystadenoma. She remained well on follow up.

\section{Case 4}

Nine year and 4 month old RH presented with early puberty that developed when she was 9 years of age. Abdominal examination was unremarkable whilst the ultrasonography showed a $3.4 \mathrm{~cm}$ solid right ovarian mass. She had prepubertal levels of gonadotrophins, a normal $\beta \mathrm{HCG}$ and a serum oestradiol of $<50 \mathrm{pmol} / 1$ (40-190). She had a laparoscopic oophorectomy. The histology showed a stromal tumour with focal proliferation of thecal cells. Her puberty progressed normally and the US scans were normal 2 years after surgery.

\section{Case 5}

MV was born following a normal pregnancy. She presented at 6 months of age with a one month history of breast and pubic hair development and 5 days of vaginal bleeding. Examination revealed a big baby (length on the 90th and weight between the 90th and 97th centiles) with no skin lesions with evidence of precocious puberty (Tanner Stage 111) and a well circumscribed mobile mass arising from the pelvis. She had very high levels of serum oestradiol and inhibin $[>2000 \mathrm{pmol} / 1 \quad(<40)$ and 91,490 u/1 (100-754) respectively]. The alpha FP, BHCG and DHEAS were within normal limits and the levels of FSH and LH were prepubertal. The ultrasonography confirmed an $8 \mathrm{~cm}$ solid and cystic complex mass arising from the right ovary. The tumour that was removed at laparotomy by a salpingo-oophorectomy was a juvenile granulosa cell tumour. There were no pubertal changes 2 months after surgery and the serum oestradiol and inhibin levels gradually normalized during follow up. She remained well and the US scans till 4 years later did not show any residual or recurrent tumour.

\section{Case 6}

SW presented at 13 months of age with a one month history of progressive abdominal distension and appearance of pubic hair associated with an increase in length. On examination she had clitoromegaly but no breast development and a distended abdomen with ascites that made the $11 \times 8 \times 10 \mathrm{~cm}$ well defined heterogeneous left ovarian mass found on ultrasonography difficult to palpate. Her testosterone and androstendione levels were raised at $21.5 \mu \mathrm{mol} / 1$ and $13.6 \mu \mathrm{mol} / 1$ respectively (these hormones are normally undetectable at this age) and she had a $17 \mathrm{OHP}$ of $9.1 \mathrm{nmol} / 1$ (normal $<5$ ). The FSH and LH were both $<1 \mathrm{u} / 1$ and the alpha FP was $15 \mu \mathrm{g} / \mathrm{L}$ (normal 0-12). The karyotype was not performed. At laparotomy there was no evidence of metastatic disease and she had a left salpingo-oophorectomy. Histologically the tumour was a Sertoli-Leydig cell tumour of intermediate differentiation with an intact capsule. The hormone levels normalized one month later and the features of virilization regressed two months after surgery. CXRs and US scans were done for $51 / 2$ years after surgery with no evidence of recurrence or metastases and she remained well during the $81 / z$ years of follow up.

\section{Case 7}

SG was transferred for chemotherapy at the age of 7 years and 2 months. She had presented with an acute abdomen and gave a one month history of increasing lethargy and poor appetite. She also had evidence of precocious puberty with breast development and appearance of pubic hair. The laparotomy revealed a large left ovarian tumour that had undergone torsion and was resected. The histology was of a mixed malignant germ cell tumour and was confirmed at the Royal Children's Hospital as a mixed teratoma and embryonal carcinoma. She had prepubertal gonadotrophin levels and normal DHEAS, testosterone and progesterone with oestradiol at $<20 \mathrm{pmol} / 1$ (normal 40-190). The BHCG and alpha FP levels which were elevated prior to treatment, normalized after $31 / 2$ years and $41 / 2$ years respectively, of commencing chemotherapy. The evidence of precocious puberty regressed after starting treatment and she remains well after $41 / 2$ years with normal US and CT scans with no evidence of recurrence of disease or metastases.

\section{Discussion}

Ovarian tumours are rare in children and most are benign $^{3,6,7}$. More than $60 \%$ are germ cell tumours in this age group while about $20 \%$ are of epithelial origin and nearly $10 \%$ are sex cord-stromal tumours ${ }^{3,6}$. Malignant ovarian tumours in childhood are very rare and the peak incidence is found in the prepubertal and pubertal age groups ${ }^{8,9}$. Germ cell tumours are the commonest malignant tumours ${ }^{6,8}$. The epithelial tumours are further classified into 
several groups depending on their histology, the commonest being serous and mucinous tumours. The stromal tumours are composed of sex cords and stroma of either male or female origin. In the female, granulosa cells form the cords while the stroma comprises of theca cells. The cords and stroma are formed by Sertoli and Leydig cells respectively in the male.

The majority of functioning lesions of the ovary synthesize oestrogen while a few produce androgens. Endocrine manifestations presenting as precocious puberty or virilization associated with ovarian lesions are $\operatorname{rare}^{3,10}$. Less than $10 \%$ of girls with precocious sexual development have primary ovarian lesions ${ }^{11}$. Both benign and malignant lesions of the ovary have been documented as producing endocrine manifestations. In a 10 year review of females below 18 years, Imai et $\mathrm{al}^{12}$ reported 4 children $(3.5 \%)$ with precocious puberty in a series of 114 ovarian tumours. Similarly, Brown et $\mathrm{al}^{7}$ reported that in an 11-year study, only 5 of 91 girls $(5.5 \%)$ diagnosed with a primary ovarian lesion at an age $<18$ years presented with precocious puberty. In the present series, we had 7 $(14.3 \%)$ out of 49 girls under 12 years of age presenting over a period of 11 years with abnormal pubertal changes associated with ovarian lesions.

The commonest cause for precocious sexual development associated with ovarian lesions is a follicular cyst of the ovary ${ }^{3,11,13}$. Multiple small follicular cysts are common findings in the ovaries of prepubertal girls ${ }^{13}$. At times, large ovarian cysts can occur producing oestrogen which causes sexual precocity in these children ${ }^{13,14}$. There are several studies reporting precocious sexual development associated with unilateral ${ }^{14,15}$ and bilateral $^{16}$ follicular cysts. Whilst the plasma and/or urinary oestradiol levels were raised in most of the patients $^{14,15}$, all of them had suppressed gonadotrophin levels ${ }^{14,15,16}$. Of the 15 patients with physiological cysts only one child with a follicular cyst presented with precocious puberty in our series.

Massive ovarian oedema, first described by Kalstone et al in $1969^{17}$, is a rare condition which is thought to be due to chronic partial torsion of the mesovariaum. Mostly seen in young women it is particularly uncommon in prepubertal girls ${ }^{17,18}$. Masculinization and secondary amenorrhoea are the usual presenting endocrine manifestations in affected adults $^{17,18}$. The 10 years and 3 month old child in this series had massive ovarian oedema following torsion of the ovarian pedicle and as described in the literature, her endocrine manifestations regressed with a reduction in the serum oestradiol levels following oophorectomy.
Granulosa-theca cell tumours of the sex cordstromal group have been the commonest ovarian tumour to be associated with precocious sexual devel-opment ${ }^{11,19,20}$. Juvenile granulosa cell tumour has been reported in association with precocious puberty in several infants and young children ${ }^{19,20,21}$. Virilization as a manifestation of sex cord-stromal tumours is rare ${ }^{11}$ but was present in a 13 month old girl in this series. Endocrine manifestations are rare in malignant ovarian tumours and usually associated with tumours of germ cell origin ${ }^{7,8,9}$. Precocious puberty was seen in a patient with a mixed teratoma and embryonal carcinoma during this period.

\section{Conclusions}

Endocrine manifestations associated with ovarian lesions are rare. Although hypersecretion of oestrogen is said to be most commonly associated with follicular cysts, it was found in relation to both benign and malignant tumours of the ovary in this series. In a young girl presenting with precocious sexual development/virilization, examining for an abdominal/pelvic mass and performing an ultrasonography of the abdomen are essential. This is especially so if the gonadotrophin levels are prepubertal.

\section{Acknowledgments}

During the period of this study K S H de Silva was a recipient of the Novo Nordisk ASEAN Paediatric Endocrine Fellowship for 1999.

\section{References}

1. Australian Bureau of Statistics. Population by age and sex, Australian states and territories. Canberra, ABS, 1999.

2. Siegel Marilyn J. Female Pelvis. In: Siegel Marilyn J, editor. Pediatric Sonography. 2nd ed. New York: Raven Press, 1995;437-77.

3. Rapaport R. Pseudoprecocity due to lesions of the ovary. In: Behrman R E, Kliegman R M, Jenson H B, editors. Nelson's Textbook of Pediatrics. $16^{\text {th }}$ ed. Philadelphia: W.B.Saunders company, 2000; 1758-9.

4. Genetic Syndromes-Skeletal Dysplasia. In: Goodman Richard M, Gorlin Robert J, editors. The Malformed Infant and Child. An Illustrated Guide. Oxford University Press, Inc. 1983;332-3. 
5. Warne G L, Hughes I A. The clinical management of ambiguous genitalia. In: Brook Charles G D editor. Clinical Paediatric Endocrinology. 3rd ed. Blackwell Science Ltd, 1995; 53-68.

6. Skinner M A, Schlatter M G, Heifetz S A, Grosfeld J L. Ovarian neoplasms in children. Arch Surg 1993; 128(8): 849-53.

7. Brown M F, Hebra A, McGeehin K, Boss A J. Ovarian masses in children: a review of 91 cases of malignant and benign masses. $J$ Pediatr Surg 1993; 28(7): 930-2.

8. Treuner J, Niethammer D, Schweizer P, Fischbach H, Flach A. Malignant ovarian tumours during childhood. Prog Pediatr Surg1983; 16: 121-6.

9. Gribbon $\mathrm{M}$, Ein S H, Mancer K. Pediatric malignant ovarian tumors: a 43 year review. J Pediatr Surg 1992; 27(4): 480-4.

10. Kelnar C J H. Endocrinological aspects of puberty and adolescence. In: Campbell A G M, Mclntosh N, editors. Forfar and Arneil's Textbook of Paediatrics. 4th ed. UK: Churchill Livingstone, 1992; 428-30.

11. Cronje H S, Niemand I, Bam R H, Woodruff J D. Granulosa and theca cell tumors in children: a report of 17 cases and literature review. Obstet Gynecol Surv1998; 53(4): 240-7.

12. Imai A, Furui T, Tamaya T. Gynaecologic tumors and symptoms in childhood and adolescence; 10 years' experience. Intern $J$ Gynaecol Obstet 1994; 45(3): 227-34.

13. Grumbach M M, Styne D M. Puberty: ontogeny, neuroendocrinology, physiology and disorders. In: Wilson J D, Foster D W, Kronenberg H M, Larsen P R, editors. Williams Textbook of Endocrinology. 9th ed. Philadelphia: W.B. Saunders company, 1998; 1587-9.
14. Low L C K, Wang C, Leung A, Leong L Y. Undetectable levels of serum FSH immunoactivity and bioactivity in girls with sexual precocity due to ovarian cysts. Acta Paediatr 1994; 83(6): 623-6.

15. Rodriguez-Macias K A, Thibaud E, Houang M, Duflos C, Beldjord C, Rappaport R. Follow up of precocious pseudopuberty associated with isolated ovarian follicular cysts. Arch Dis Child 1999; 81(1): 53-6.

16. Sinnecker G, Willig R P, Stahnke N, Braendle W. Precocious pseudopuberty associated with multiple ovarian follicular cysts and low plasma oestradiol concentrations. Euro $J$ Pediatr1989; 148(7): 600-2.

17. Alberda A T, Wladimiroff $\mathrm{J}$ W, Wielenga G, Verschoor L. Massive ovarian oedema. Case report. Br J Obstet Gynaecol 1981; 88(5): 56973 .

18. Eden J A. Massive ovarian oedema. $\mathrm{Br} J$ Obstet Gynaecol 1994; 101 (5): 456-8.

19. Bouffet E, Basset T, Chetail N, Dijoud F, Mollard P, Brunat-Mentigny $\mathrm{M}$, David $\mathrm{M}$. Juvenile granulosa tumour of the ovary in infants: a clinicopathologic study of three cases and review of the literature. $J$ Pediatr Surg 1997; 32(5): 762-5.

20. Raafat F, Klys H, Rylance G. Juvenile granulosa cell tumor. PediatrPathol 1990; 10(4): 617-23.

21. Cameron F J, Scheimberg I, Stanhope R. Precocious pseudopuberty due to a granulosa cell tumour in a seven month old female. Acta Paediatr 1997; 86(9): 1016-8.

22. Jolles C J. Ovarian Cancer: Histogenetic Classification, Histologic Grading, Diagnosis, Staging and Epidemiology. In: Clinical Obstetrics and Gynaecology. Pennsylvania: Harper and Row Publishers, Inc, 1985; 28(4): 787-799. 